\title{
Fracture behavior of quenched poly(lactic acid)
}

\author{
J. Gámez-Pérez*1, J. C. Velazquez-Infante1, E. Franco-Urquiza ${ }^{1}$, P. Pages ${ }^{2}$, F. Carrasco ${ }^{3}$, \\ O. O. Santana ${ }^{1}$, M. Ll. Maspoch ${ }^{1}$
}

${ }^{1}$ Centre Català del Plàstic (CCP), Universitat Politècnica de Catalunya C/Colon 114, 08222 Terrassa, Spain

${ }^{2}$ Materials Science Departament - ETSEIAT, Universitat Politecnica de Catalunya C/Colon 11, 08222 Terrassa, Spain

${ }^{3}$ Department of Chemical Engineering, Universitat de Girona, Campus de Montilivi, s/n. 17071 Girona, Spain

Received 1 July 2010; accepted in revised form 29 September 2010

\begin{abstract}
The effect of a quenching treatment applied on heated cast sheet extruded films of two poly(lactic acid) (PLA) commercial grades, with different optical purities, was studied. The thermal and mechanical properties of the films, as well as their fracture behavior, were assessed by differential scanning calorimetry (DSC), tensile tests, and the essential work of fracture (EWF) approach. The heating-quenching treatment causes a de-aging effect with an increase in the free volume of polymer chains evidenced by a decrease in the glass transition temperature $\left(T_{\mathrm{g}}\right)$ and a decrease in the tensile stiffness and yield stress. As a result, there is an abrupt increase in ductility, finding a dramatic change in the fracture behavior, from brittle to ductile. The use of digital image correlation (DIC) of the strain field analysis during fracture testing has allowed relating the decrease on the yield stress promoted by quenching with the crack propagation kinetics. The use of the EWF method to characterize the fracture toughness of PLA has allowed to measure this enhancement on toughness, finding that the specific essential work of fracture $\left(w_{\mathrm{e}}\right)$ and the plastic term $\left(\beta w_{\mathrm{p}}\right)$ parameters increased $120 \%$ and $1200 \%$, respectively, after the quenching process.
\end{abstract}

Keywords: mechanical properties, poly(lactic acid) PLA, essential work of fracture (EWF), physical aging

\section{Introduction}

Poly(lactic acid) (PLA) is a semi-crystalline biodegradable polymer that has been used for several years in medical and biocompatible applications [1]. The commercial PLA is synthesized from lactic acid, which comes from renewable sources and at the present is the biopolymer with the fastest consumption growth rate [2], finding an increasing interest in the development of novel applications for other industrial sectors, such as houseware, packaging, etc. The lactic acid used to produce commercial PLA is in fact a stereo isomer, where the L-lactic acid monomer is the main component and the D-lactic acid stereoisomer is present as impurity, affecting the ability to crystallize and the final properties of PLA [3].
The glass transition $\left(T_{\mathrm{g}}\right)$ and melting $\left(T_{\mathrm{m}}\right)$ temperatures of PLA are around 60 and $155^{\circ} \mathrm{C}$, respectively. However, its rate of crystallization from the melt is quite slow if compared with the cooling rates found in typical industrial transformation processes $[4,5]$. As a consequence, commercial PLA products are mainly found in the glassy state, and thus can experience physical aging [6]. With aging, a molecular reorganization process, which originates the presence of ordered domains or more organized zones, is produced. This reordering is known also as densification and causes a considerable decrease in the free volume $\left(v_{\mathrm{f}}\right)$. The molecular mobility and the entanglement density are determined by the $v_{\mathrm{f}}$, which in turn limits the ability of the material to store and dissipate energy when it is 
mechanically stressed. This aging phenomenon occurs in a broad temperature range between $T_{\mathrm{g}}$ and the first (highest) secondary transition, $T_{\beta}[7]$ and can induce a decrease in ductility and increase in stiffness.

The effects originated by the physical aging of the PLA have been the object of study during the last few years [8-11]. The mechanical behavior is one of the research areas studied, and it was found that the mechanical properties varied with aging time. The modulus and yield stress presented a similar step growing trend until they reached a plateau after $1000 \mathrm{~h}$ of aging. Strain at break, meanwhile, presented a rapid decrease from 300 to $6 \%$ at room temperature in $24 \mathrm{~h}$, remaining practically constant thereafter [11]. Therefore, the brittleness of PLA at room temperature can be viewed as a consequence of the physical aging process. Nevertheless, in spite of these advances, studies describing the effect of aging on the structure-properties relationship of the fracture behavior of PLA are not yet known.

As physical aging does not involve permanent changes in the material structure, it can be regarded as a reversible process. The inverse process, hereafter called de-aging, can be caused by a thermal treatment at $T_{\mathrm{g}}$ (or a slightly higher temperature) followed by quenching. Heating at that temperature increases the molecular mobility of the polymeric chains and eliminates the pseudo-ordered or more organized domains generated during aging. Accordingly, such treatment also generates an increase in the $v_{\mathrm{f}}$, resulting in a looser packing structure, similar to that above $T_{\mathrm{g}}$. The sudden cooling freezes this less ordered structural state and hampers a chain reorganization such as the one caused by aging during slow cooling. Even though physical aging on toughness behaviour of polymers has been little investigated using fracture mechanics approaches, the essential work of fracture method (EWF) has been reported as a successful technique to follow the effect of physical aging on polymer films [12-16]. The aim of this work consists in the application of a de-aging thermal treatment to two commercial grades of PLA with different D-lactic monomer fractions and studying their fracture behavior applying the EWF method.

\section{Experimental part}

\subsection{Materials and processing}

In this study, two commercial grades of PLA from NatureWorks ${ }^{\circledR}$ (2002D and 4032D) were used. These grades have different D-lactic monomer contents, 4.25 and $2 \%$ respectively [17-20], and weight average molecular weights, 212 and $207 \mathrm{kDa}$ respectively, assessed by Gel Permeation Chromatography (GPC) [21]. Sheets with both materials were obtained by cast sheet extrusion in a single-screw COLLIN Teach-Line ${ }^{\circledR}$ E16T extruder $(T=145-$ $\left.200^{\circ} \mathrm{C}, 50 \mathrm{rpm}\right)$. Before processing, the materials were dried in a PIOVAN dehumidifier $\left(T=80^{\circ} \mathrm{C}\right.$, $t=3 \mathrm{~h}$ ) to prevent hydrolysis. The chill rolls temperature was set to $50^{\circ} \mathrm{C}$.

All test specimens were cut along the film production (MD) direction. De-aging of the sheets was performed in an oven at $60^{\circ} \mathrm{C}$ for $20 \mathrm{~min}$., followed by quenching in an iced water bath. In order to maintain the form of the sheets, they were placed between two steel plates during heating and quenching. All tests were carried out immediately after the de-aging treatment. For comparison purposes, samples that had not been thermally treated were also tested. The nomenclature employed was PLA-X and PLA-XT for extruded and thermally treated films respectively, where $\mathrm{X}$ is set as 96 for PLA with $95.75 \%$ L-lactic monomer and 98 for PLA with 98\% L-lactic monomer, and $T$ represents the thermal treatment of de-aging followed by quenching.

\subsection{Thermal characterization}

Differential scanning calorimetry (DSC) data from samples were obtained in a Perkin Elmer calorimeter, model Pyris 1 (with 2P intracooler). Temperature and enthalpy calibration was performed using indium and lead. Samples of approximately $10 \mathrm{mg}$ taken from the central sections of test specimens were sealed in aluminium pans and subjected to heating from 30 to $200^{\circ} \mathrm{C}$ at $10^{\circ} \mathrm{C} / \mathrm{min}$. under a dry nitrogen atmosphere. From thermograms, the midpoint glass transition temperature $\left(T_{\mathrm{g}}\right)$, melting temperature $\left(T_{\mathrm{m}}\right)$, cold crystallization enthalpies $\left(\Delta H_{\mathrm{cc}}\right)$, and melting enthalpy $\left(\Delta H_{\mathrm{m}}\right)$ were recorded following ISO 11357-3:1999 and ISO 11357-2:1999 standards. 


\subsection{Mechanical and fracture characterization}

The mechanical characterization was performed by means of tensile tests according to the ASTM D-638 standard. Tests were carried out in a universal testing machine Galdabini Sun 2500 (Italy), equipped with a $5 \mathrm{kN}$ load cell. A standard specimen's geometry type IV was used. Deformations were followed with a video extensometer, a Mintron OS-65D CCD (Taipei, Taiwan) video camera in conjunction with Messphysik (Fürstenfeld, Austria) Windows based software. Yield stress $\left(\sigma_{\mathrm{y}}\right)$, Young's modulus $(E)$, and strain at break $\left(\varepsilon_{\mathrm{b}}\right)$ were assessed. Each value is the average of five valid tests.

The fracture behavior of materials that present high plastic deformation can be described by post-yielding fracture mechanics (PYFM). The Essential Work of Fracture method (EWF) provides a technique for obtaining toughness parameters for the ductile fracture process in either tensile [22-24] or tearing [25] configurations. Deeply Double Edge Notched Tensile (DDENT) specimens are the most used geometry in EWF determinations in tensile mode. However, for the correct application of the EWF method, some experimental constraints must be taken into account. The ligament length should be in a range that guarantees: (1) pure plane stress conditions, (2) no border effect, (3) full yielding of the ligament length prior to crack propagation, and (4) a geometrical similarity between the load vs. displacement $(F-d)$ curves of specimens with different ligament lengths [22].

The EWF concept states that the energy involved during a ductile fracture $\left(W_{\mathrm{f}}\right)$ can be partitioned into two components. One component, the essential work $\left(W_{\mathrm{e}}\right)$ is associated with the energy spent in the inner fracture process zones (FPZ) and is therefore proportional to the fracture area $(\ell \cdot t)$, where $\ell$ is the ligament length and $t$ is the specimen width. The second component is the non-essential work of fracture or plastic work $\left(W_{\mathrm{p}}\right)$, which is related to the energy of the process that takes place in the outer plastic deformation zone, called also the plastic zone (OPZ). As it is related to plastic deformation and other dissipative processes, $W_{\mathrm{p}}$ is proportional to the volume of the deformed region $\left(\ell^{2} \cdot t\right)$ surrounding the crack process zone. The relation between $W_{\mathrm{f}}, W_{\mathrm{e}}$, and $W_{\mathrm{p}}$ can be expressed by Equation (1):

$W_{\mathrm{f}}=W_{\mathrm{e}}+W_{\mathrm{p}}=w_{\mathrm{e}} \ell t+w_{\mathrm{p}} \beta \ell^{2} t$ where $\beta$ is a shape factor for the plastic zone. Expressing both members of Equation (1) in their specific terms results in a direct relationship between the specific fracture energy $\left(w_{\mathrm{f}}\right)$ and $\ell$ (Equation (2)):

$w_{\mathrm{f}}=w_{\mathrm{e}}+\beta w_{\mathrm{p}} \ell$

According to Equation (2) the essential work of fracture $\left(w_{\mathrm{e}}\right)$ and the plastic term $\left(\beta w_{\mathrm{p}}\right)$ can be obtained from linear regression of a set of values represented in a diagram of specific fracture energy versus ligament length ( $w_{\mathrm{f}}$ vs. $\ell$ ). More information about the testing procedure and applicability of the EWF technique can be found in two recent reviews of the EWF method [26, 27].

The specimens used in this work are rectangular DDENT with nominal dimensions of $60 \times 30 \times$ $0.30 \mathrm{~mm}^{3}$. Five ligament lengths between 5 and $25 \mathrm{~mm}$ with a step of $5 \mathrm{~mm}$ were tested. For each ligament length, three specimens were investigated. Deformation was followed with a video-extensometer following the procedure described in a previous work [28]. The crosshead speed for mechanical and fracture characterization was $1 \mathrm{~mm} / \mathrm{min}$ and tests were conducted at room temperature $\left(22 \pm 1^{\circ} \mathrm{C}\right)$.

\subsection{Strain field analysis}

In order to validate the applicability of the EWF method to the four materials studied, DDENT samples with three different ligament lengths were tested. A commercially available optical strain measurement system (ARAMIS ${ }^{\circledR}$, which is a trade name of the equipment from GOM GmbH, Braunschweig, Germany) that utilizes two digital cameras and the digital image correlation (DIC) methodology was used to asses the strain distribution with respect to both time and space in the three axes. Therefore, point to point sample thickness variation during testing can be recorded and analyzed.

\section{Results and discussion}

\subsection{Thermal characterization}

DSC first heating curves for PLA samples are shown in Figure 1. In the curves corresponding to samples without thermal treatment, it can be observed an endothermic peak around $63^{\circ} \mathrm{C}$, right after the mid-point glass transition temperature, shown in Table 1. This is a typical signal shown by physically aged glassy polymers. The area under 


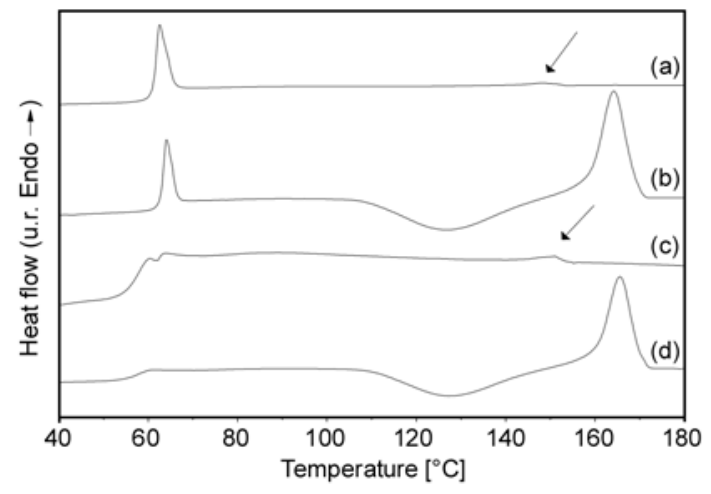

Figure 1. First heating DSC curves of PLA-96 (a), PLA-98 (b), PLA-96T (c), and PLA-98T (d)

Table 1. Effect of the de-aging treatment on the thermal properties of PLA-96 and PLA-98

\begin{tabular}{|l|c|c|r|r|}
\hline $\begin{array}{c}\text { Thermal } \\
\text { properties }\end{array}$ & PLA-96 & PLA-96T & PLA-98 & PLA-98T \\
\hline$T_{\mathrm{g}}\left[{ }^{\circ} \mathrm{C}\right]$ & $60.1 \pm 0.1$ & $56.0 \pm 0.1$ & $61.3 \pm 0.5$ & $57.1 \pm 0.4$ \\
\hline$T_{\mathrm{m}}\left[{ }^{\circ} \mathrm{C}\right]$ & $148.0 \pm 0.5$ & $148.4 \pm 0.6$ & $164.1 \pm 0.1$ & $165.2 \pm 0.5$ \\
\hline$\Delta H_{\mathrm{cc}}[\mathrm{J} / \mathrm{g}]$ & - & - & $29.2 \pm 1.4$ & $30.7 \pm 0.4$ \\
\hline$\Delta H_{\mathrm{m}}[\mathrm{J} / \mathrm{g}]$ & $0.80 \pm 0.01$ & $1.3 \pm 0.3$ & $31.2 \pm 0.4$ & $33.5 \pm 0.2$ \\
\hline$X_{\mathrm{c}}[\%]$ & $0.86 \pm 0.02$ & $1.4 \pm 0.3$ & $2.2 \pm 1.1$ & $3.0 \pm 0.7$ \\
\hline
\end{tabular}

the endothermic peak at $T_{\mathrm{g}}$ corresponds to the excess enthalpy of relaxation $\left(\Delta H_{\mathrm{rel}}\right)$ [29] and can be used as an indicator of aging [30, 31]. When glassy polymers are fast cooled, they are in a metastable state with an excess of enthalpy, entropy, and volume, which is far from the thermodynamic equilibrium. This excess in thermodynamic properties acts as driving force for a slow and gradual approach toward the thermodynamic equilibrium, originating a decrease in the free volume of the polymer. The change in $v_{\mathrm{f}}$ is accompanied by a simultaneous decrease in the segmental mobility. As a result, the aged PLA has less enthalpy and potential energy than the just cooled one. Therefore, when the material is reheated, more energy $\left(\Delta H_{\text {rel }}\right)$ is needed for the glass transition to take place. De-aged samples did not show the $\Delta H_{\text {rel }}$ endothermic peaks (Figures 1c and 1d), indicating that the state of aging was completely erased. Besides, an exothermic peak (cold crystallization) can only be appreciated in the PLA-98 samples (Figures $1 \mathrm{~b}$ and $1 \mathrm{~d}$ ). PLA cold crystallization is affected by the rate of heating, the optical purity (Llactic isomer content present in the material), and the previous thermal history experienced by the material [32-34]. In this case, the lower L-lactic content of both PLA-96 samples reduces its crystallization rate. Consequently, PLA-96 samples need a greater time for cold crystallization than that used in the experimental conditions.

In Figure 1, endothermic peaks corresponding to the fusion of PLA crystallites can be identified at around $148^{\circ} \mathrm{C}$ in the case of PLA-96 samples and at around $165^{\circ} \mathrm{C}$ for PLA-98 ones. PLA-98 samples showed a stronger fusion signal than the PLA-96 ones did (identified with an arrow in Figure 1) due to a greater crystal population, originated by cold crystallization during heating.

Crystallinity $\left(X_{\mathrm{c}}\right)$ was determined from the measured $\Delta H_{\mathrm{cc}}$ and $\Delta H_{\mathrm{m}}$ based on the Equation (3) [4]:

$X_{\mathrm{c}}=\frac{\Delta H_{\mathrm{m}}-\Delta H_{\mathrm{cc}}}{\Delta H_{0}} \cdot 100$

where $\Delta H_{0}$ corresponds to the enthalpy of fusion of the theoretical $100 \%$ crystalline PLA. In this study $\Delta H_{0}$ was take as $93 \mathrm{~J} / \mathrm{g}$ [35]. All calculations were made based on data obtained from the first heating. Table 1 summarizes the values of $X_{\mathrm{c}}, T_{\mathrm{g}}$, and $T_{\mathrm{m}}$ determined from first heating thermograms of all materials.

It was found that samples without thermal treatment of both PLAs showed the glass transition at higher temperature values. Aging reduces segmental mobility, making it necessary to heat the samples up to higher temperature values to allow the glass transition to occur, resulting in the higher $T_{\mathrm{g}}$ values observed. Besides, it was also found that PLA-98 samples had higher values of $T_{\mathrm{m}}$. The melting point of a semicrystalline polymer is determined by the size and perfection of its crystals (i.e. by the lamellar thickness). Higher optical purity gives more structural regularity to PLA-98 samples, and therefore it can form crystals of higher lamellar thickness during the cold crystallization that takes place at the first heating scan. The low $X_{\mathrm{c}}$ values indicate that in all cases the sheets are essentially amorphous. Moreover, there is no evidence that the crystallinity or the cold crystallization ability were affected by the de-aging thermal treatment.

\subsection{Mechanical characterization}

Stress-strain curves for samples with and without de-aging thermal treatment are shown in Figure 2. The original sheets which had not been de-aged are stiffer, with higher yield stress and lower elongation at break, than the de-aged ones. Post-mortem test samples of PLA-98 and PLA-98T, shown in 


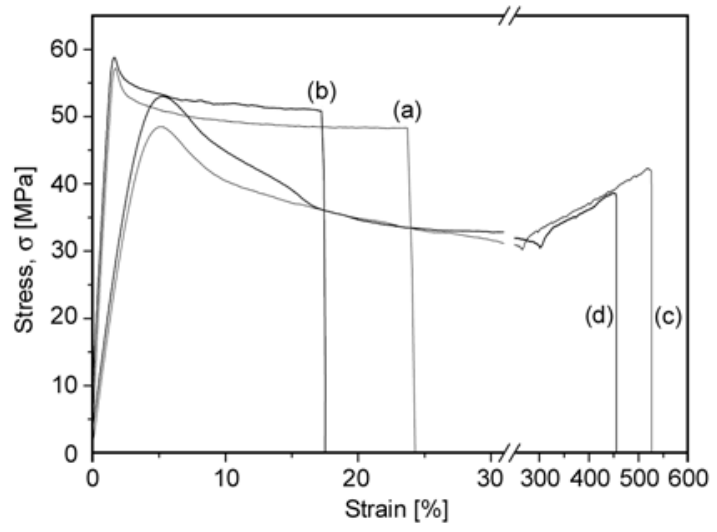

Figure 2. Stress-strain diagrams of (a) PLA-96, (b) PLA98, (c) PLA-96T, and (d) PLA-98T

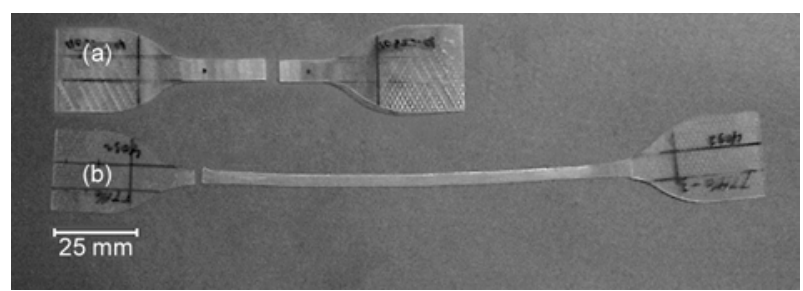

Figure 3. Post-mortem tensile test samples: (a) not thermally treated (PLA-98), and (b) with thermal treatment (PLA-98T)

Figure 3, clearly evidence the differences seen in the strain-stress curves. Samples without thermal treatment showed yielding without necking and presence of crazes (Figure 3a), while a more ductile behavior, characterized by localized shear yielding and neck formation, was shown by the de-aged ones (Figure 3b). PLA-96 and PLA-96T showed behaviors similar to those seen for PLA-98 and PLA-98T respectively. As explained, aging causes a molecular reorganization with reduction of free volume, resulting in a more packed structure with lower potential energy. Since molecules attract one to another, the decrease of free volume is accompanied by decrease in potential energy of the polymer. Consequently, the stress required for establishing yielding during tensile testing, which is related to the variation of potential energy, will be greater in samples with lower potential energy in the ground state or vice versa. On the other hand, the increase in the free volume of the polymer chains caused by the de-aging treatment and the displacement of the glass transition to lower values of temperatures result in a greater mobility of the polymer chains, permitting more local strain to be achieved. These observations are in agreement with results obtained by Pan et al. [11].
Table 2. Tensile parameters of PLA-96 and PLA-98 before and after the quenching treatment

\begin{tabular}{|l|c|c|c|c|}
\hline $\begin{array}{c}\text { Mechanical } \\
\text { properties }\end{array}$ & PLA-96 & PLA-96T & PLA-98 & PLA-98T \\
\hline$\sigma_{\mathrm{y}}[\mathrm{MPa}]$ & $56.2 \pm 0.7$ & $47.3 \pm 1.1$ & $58.4 \pm 0.5$ & $53.4 \pm 0.6$ \\
\hline$E[\mathrm{GPa}]$ & $4.0 \pm 0.2$ & $3.3 \pm 0.2$ & $4.3 \pm 0.1$ & $3.5 \pm 0.3$ \\
\hline$\varepsilon_{\mathrm{b}}[\%]$ & $24 \pm 5$ & $456 \pm 100$ & $17 \pm 4$ & $422 \pm 50$ \\
\hline
\end{tabular}

Table 2 summarizes the average values obtained from the mechanical test assessed for all materials under study. From that data, it can be said that, on the whole, samples of PLA-98 have slightly higher values of modulus and yield stress but lower elongation at break than their PLA-96 counterpart samples. When comparing the mechanical properties of both PLA grades in depth, it can be found that only in the case of the thermally treated specimens, differences in $E$ and $\sigma_{\mathrm{y}}$ are pronounced. It is well known that the deformation mechanisms involved in amorphous polymer systems below their $T_{\mathrm{g}}$ are controlled by the molecular entanglements density and the chain stiffness or characteristic ratio $\left(C_{\infty}\right)$. Joziasse et al. [36] found in a previous work that there is an inverse relationship between $C_{\infty}$ and the D-lactic isomer content present in PLA copolymers. Therefore, the chain stiffness increases with stereoregularity. In the case of de-aged specimens, the polymer chains present higher mobility, free volume and a less packed structure than the non thermally treated ones. The higher D-lactic isomer content of PLA-96T makes the polymer chains to be more flexible than those of PLA-98T, resulting in lower elastic modulus and yield stress. Regarding the influence of de-aging and quenching, it can be pointed out that PLA-96 and PLA-98 are influenced by the intermolecular interactions resulting from the densification produced during aging, which result in higher stiffness and yield stress. Such increase in the mechanical properties caused by aging hinders the effect of the chain stiffness when comparing both PLA grades, attributing the slightly higher values of modulus and yield stress of the PLA-98 to the small variations in crystallinity [37].

\subsection{Fracture behavior}

\subsubsection{Strain field analysis}

As pointed out in the experimental section, in order to validate the applicability of the EWF method, the strain distributions in the OPZ and FPZ from samples with different ligament lengths were deter- 


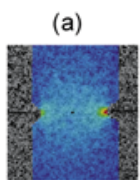

(b)
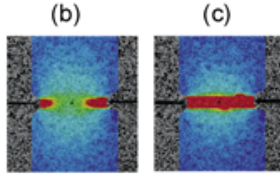

(d)
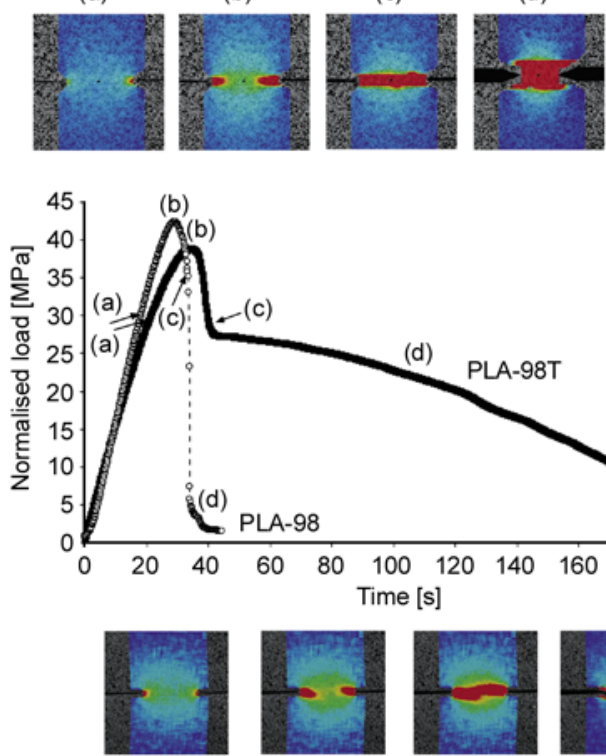

(a) (c)

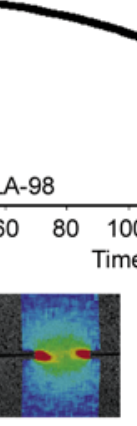

(b) (e)

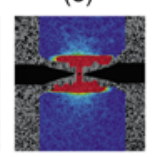

$[\%]$

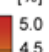

4.5
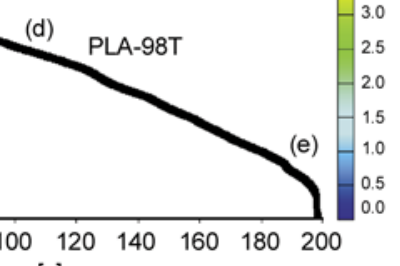

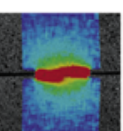

(c)

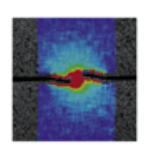

(d)
Figure 4. Time-resolved strain field analysis showing the crack growth and thickness variation for DDENT samples of PLA-98 and PLA-98T with $\ell=$ $10 \mathrm{~mm}$. The normalised load reported on the $y$-axis has been calculated as the testing load divided by the initial ligament section.

mined using digital image correlation (DIC) methodology. As an example, load-time curves of PLA-98 and PLA-98T samples with $\ell \sim 10 \mathrm{~mm}$ are shown in Figure 4. In this figure, the plastic and elastic deformations near the crack tip are evidenced, showing the evolution of the thickness reduction of the specimens during the crack growth. Similar load-time curves for PLA-96 and PLA-96T, respectively, were also found.

By observing the deformation map surrounding the notch ligament in time, the onset of crack propagation can be established with DIC data. As an example, point (c) of Figure 4 was determined as the onset of crack propagation. Following such analysis, it can be proved that the ligament yielded before the onset of crack initiation for de-aged materials (PLA-96T and PLA 98-T), demonstrating the applicability of the EWF concept to these films. Furthermore, the curves in Figure 4 show the development of a yielding area ahead of the crack tips simultaneously in both sides of the DDENT specimen, thus validating the uniformity of the notch sharpening procedure.

When comparing both curves in Figure 4, the differences in the crack propagation kinetics after point (c) can be appreciated, leading to a change

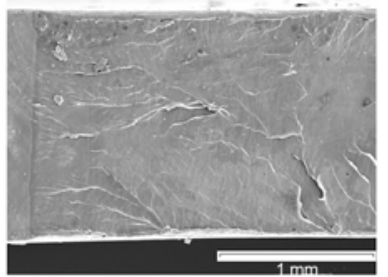

a)

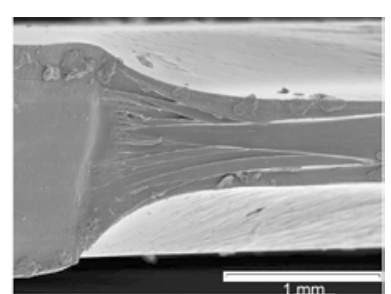

b)
Figure 5. SEM microphotographs corresponding to notch zones of PLA-98 (a) and PLA-98T (b) of postmortem DDENT specimens $(\ell=10 \mathrm{~mm})$

form brittle to tough fracture behavior promoted only by the de-aging treatment. Similar results were found in the cases of PLA-96 and PLA-96T.

As seen in Figure 4, the maximum normalized load reached in the case of PLA-98 is higher than in the case of PLA-98T, along with a decrease in the time at which this point is reached. At this point (b), a deformation halo that corresponds to elastic deformations (lower than 3\%) can be observed. As PLA98T has more free volume, it can undergo the yield phenomenon at a lower stress level than PLA-98, partially absorbing the elastic energy as plastic deformation and stable crack growth. In PLA-98 samples, on the other hand, the fast elastic energy recovering process results in unstable crack growth, resulting in a premature brittle failure.

The thickness variations assessed by DIC data were corroborated with scanning electron microscopy (SEM) of post-mortem specimens. In Figure 5 are shown, as an example, SEM microphotographs from PLA-98 and PLA-98-T, where a thickness reduction around $5 \%$ and $60 \%$ respectively can be observed.

\subsubsection{Essential work of fracture}

The EWF methodology was applied to all samples under study. Figure 6 shows an example of loaddisplacement $(F-d)$ curves obtained for PLA-96 and PLA-96T. From these curves, the criterion of selfsimilarity can be corroborated, as in case of the thermally treated materials (Figure $6 \mathrm{~b}$ ). In the case of then non thermally treated specimens, curves show a common behavior in the $10-25 \mathrm{~mm}$ range of ligament lengths (Figure 6a). Such likenesses are reflected in a similar initial slope of the curves, up to the maximum load, and parallel tails after the onset of crack propagation. Due to the fast crack growth of these specimens, some tearing at the end of the specimen fracture can introduce some remark- 

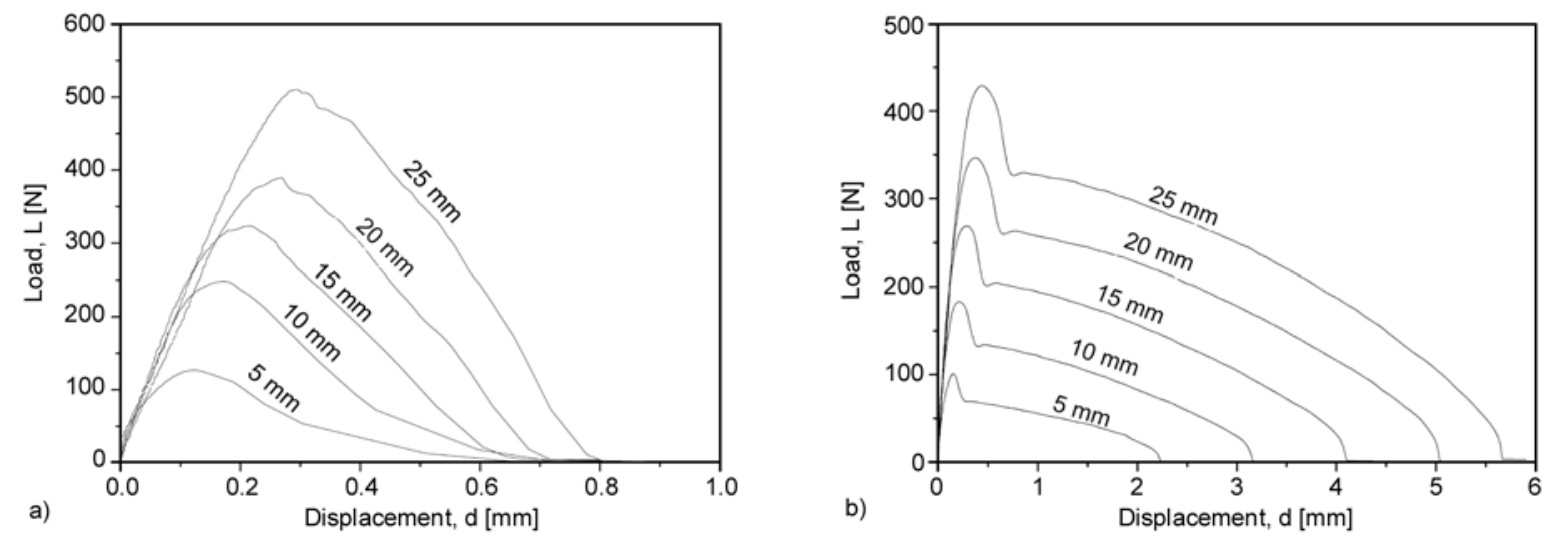

Figure 6. Load-displacement diagrams as a function of the ligament length $(\ell)$ of PLA-96 (a) and PLA-96T (b)

able discontinuities in the $L-d$ curves, especially visible in the lower ligament lengths, as a gentle load drop in the final stages of the specimen rupture.

From tests it was determined that requisites for applying the EWF method were only clearly fulfilled in de-aged materials. Materials without thermal treatment (PLA-96 and PLA-98), did not fully satisfy the EWF requisites of stable crack growth, even though showing a similar fracture geometry. Nevertheless, as observed in the diagrams of $w_{\mathrm{f}}$ versus $\ell$. Shown in Figure 7, the non thermally treated PLA exhibited a linear relationship between $w_{\mathrm{f}}$ and $\ell$, permitting the determination of the fracture parameters. These parameters, since the specimens did not fulfill all the prerequisites considered in the EWF theory, can not be used for performing exact quantitative comparisons, but qualitative ones. The regression coefficients, in the range of 0.7 and 0.8 , confirm a good linear relationship between $w_{\mathrm{f}}$ and $\ell$, allowing the use of the calculated $w_{\mathrm{e}}$ and $\beta w_{\mathrm{p}}$ parameters, to reasonably analyze the influence of the thermal treatment on the fracture behavior of the PLA films.

From comparison of these data with the fracture parameters calculated for thermally treated materials, changes caused by the de-aging treatment in the toughness of PLA can be determined. Table 3 summarizes the fracture data for all samples.

It is evident from data summarized in Table 3 that the thermal treatment caused a drastic change in the fracture parameters of the two PLA used, evidenced by the noticeable increment in $w_{\mathrm{e}}$ of $120 \%$ and in $\beta w_{\mathrm{p}}$ of $1200-1300 \%$. When comparing the different PLA grades, it can be seen that samples without thermal treatment (PLA-96 and PLA-98) have similar $w_{\mathrm{e}}$ values, which are higher than the GIC value estimated by the application of the linear elastic

Table 3. Assessment of the specific essential work of fracture $\left(w_{\mathrm{e}}\right)$ and plastic term $\left(\beta w_{\mathrm{p}}\right)$ of all materials

\begin{tabular}{|l|l|l|l|r|}
\hline $\begin{array}{c}\text { Fracture } \\
\text { parameters }\end{array}$ & PLA-96 & PLA-96T & PLA-98 & PLA-98T \\
\hline$w_{\mathrm{e}}\left[\mathrm{kJ} / \mathrm{m}^{2}\right]$ & $15.9 \pm 0.8$ & $34.1 \pm 1.7$ & $16.4 \pm 0.8$ & $37.9 \pm 1.5$ \\
\hline$\beta w_{\mathrm{p}}\left[\mathrm{MJ} / \mathrm{m}^{3}\right]$ & $0.29 \pm 0.04$ & $4.4 \pm 0.1$ & $0.28 \pm 0.04$ & $3.7 \pm 0.1$ \\
\hline
\end{tabular}

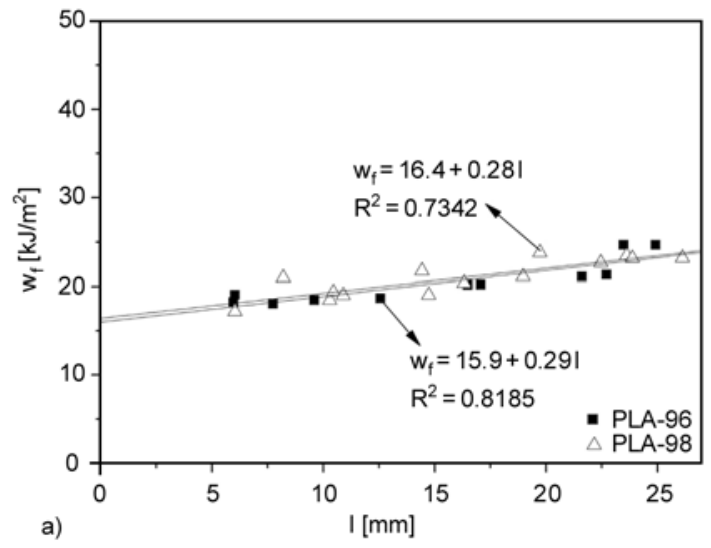

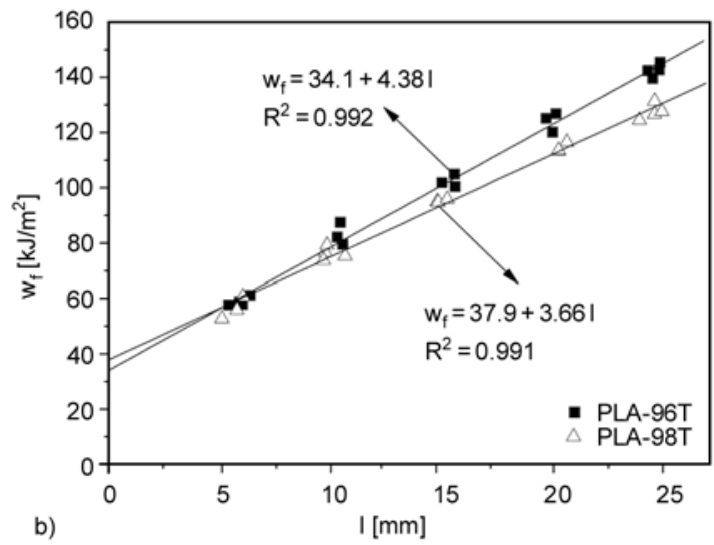

Figure 7. Specific work of fracture as a function of the ligament length for non-treated materials (a) and de-aged materials (b) 
fracture mechanics (LEFM). In the case of $6.3 \mathrm{~mm}$ thick injection molded samples of PLA-96, $G_{\text {IC }}$ was estimated by our group to be $2.4 \mathrm{~kJ} / \mathrm{m}^{2}$ [38] and $6.5 \mathrm{~kJ} / \mathrm{m}^{2}$ by Park et al. on $5 \mathrm{~mm}$ thick hot-press plates, using a PLA with 98\% L-lactic isomer content [39]. The differences observed between those values can be attributed to the different state of tension (plane stress in the case of the films and plain strain for the thicker specimens), which entails a reduction on the fracture toughness [40].

In the case of de-aged materials, it was found that PLA-98T presents a slightly greater $w_{\mathrm{e}}$ value than PLA-96T. According to Mai and colleagues [41], since $w_{\mathrm{e}}$ involves the plastic deformation processes of necking the ligament section (FPZ) and the work needed for the cracks to start growing, consequently, $w_{\mathrm{e}}$ will be greater the higher the $\sigma_{\mathrm{y}}$ and the higher the strain at necking $\left(\varepsilon_{\mathrm{y}}\right)$, as was the case for PLA-98T compared to PLA-96T in tensile testing (Table 2). Following the same reasoning, the stress versus strain curves in Figure 2 show that the areas under the $\sigma-\varepsilon$ curves, limited by the yielding point, for the de-aged materials are greater than those for their corresponding non-treated samples, justifying the greater values observed for $w_{\mathrm{e}}$.

With respect to $\beta w_{\mathrm{p}}$, the values obtained for deaged materials are much higher than corresponding ones for the non-treated ones (Table 3). Such differences can be related to the plastic deformation developed around the ligament net section, which can be observed in post-mortem DDENT specimens (Figure 5).

When both de-aged grades are compared, it can be seen that the highest $\beta w_{\mathrm{p}}$ values corresponded to PLA-96T. Arkhireyeva and colleagues found that $\beta w_{\mathrm{p}}$ increases with increasing ductility and decreases with increasing $\sigma_{\mathrm{y}}[42]$. The mechanical tests performed are consistent with Arkhireyeva's work, since PLA-96T presented higher $\varepsilon_{\mathrm{b}}$ but lower $\sigma_{\mathrm{y}}$ (Table 2).

From these results it can be foreseen that a thermal treatment applied to PLA could favor its toughness resistance for a certain period of time. This treatment could be used prior to some machining operations, such as punching or drilling, to avoid a premature brittle failure.

\section{Conclusions}

The heating at temperatures close to $T_{\mathrm{g}}$ and subsequent quenching treatment produces a de-aging effect, with an increase of the free volume of polymeric chains, evidenced by the displacement of the glass transition to lower temperatures and the increase in the system potential energy (disappearance of the endothermic peak at $T_{\mathrm{g}}$ ).

As a consequence, quenching promotes a brittle-toductile change in the fracture behavior of PLA, regardless of the D-lactic isomer content, with a decrease on the tensile strength, appearance of shear yielding and a localized and neck formation. The fracture parameters, assessed by the EWF method, show a great enhancement of the toughness after the de-aging and quenching treatment.

Regarding the influence of the D-lactic isomer content in PLA films, when they are in a glassy aged state there are no remarkable differences in the mechanical properties and fracture behavior. Only when the films are in a de-aged form, the differences in the chain stiffness of both PLA grades are revealed: the higher the optical purity, the higher the elastic modulus and tensile strength but lower deformation at break. Also, $w_{\mathrm{e}}$ increases with increasing optical purity, but the plastic term $\left(\beta w_{\mathrm{p}}\right)$ decreases.

\section{Acknowledgements}

The authors wish to thank the Spanish Science and Education Ministry for financial support through the projects MAT 2007-62450 and MAT 2010-19721. J. Velazquez is grateful to AECID for the concession of a pre-doctoral grant.

\section{References}

[1] Griffith L. G.: Polymeric biomaterials. Acta Materialia, 48, 263-277 (2000). DOI: 10.1016/S1359-6454(99)00299-2

[2] Lim L-T., Auras R., Rubino M.: Processing technologies for poly(lactic acid). Progress in Polymer Science, 33, 820-852 (2008).

DOI: $10.1016 /$ j.progpolymsci.2008.05.004

[3] Sarasua J. R., Arraiza A. L., Balerdi P., Maiza I.: Crystallinity and mechanical properties of optically pure polylactides and their blends. Polymer Engineering and Science, 45, 745-753 (2005).

DOI: 10.1002/pen.20331 
[4] Auras R., Harte B., Selke S.: An overview of polylactides as packaging materials. Macromolecular Bioscience, 4, 835-864 (2004).

DOI: $10.1002 /$ mabi.200400043

[5] Miyata T., Masuko T.: Crystallization behaviour of poly(L-lactide). Polymer, 39, 5515-5521 (1998). DOI: 10.1016/S0032-3861(97)10203-8

[6] Hutchinson J. M.: Physical aging of polymers. Progress in Polymer Science, 20, 703-760 (1995). DOI: 10.1016/0079-6700(94)00001-I

[7] Strum L. C. E.: Physical aging in plastics and other glassy materials. Polymer Engineering and Science, 17, 165-173 (1977). DOI: $10.1002 /$ pen.760170305

[8] Pluta M., Murariu M., Alexandre M., Galeski A., Dubois P.: Polylactide compositions. The influence of ageing on the structure, thermal and viscoelastic properties of PLA/calcium sulfate composites. Polymer Degradation and Stability, 93, 925-931 (2008). DOI: 10.1016/j.polymdegradstab.2008.02.001

[9] Acioli-Moura R., Sun X. S.: Thermal degradation and physical aging of poly(lactic acid) and its blends with starch. Polymer Engineering and Science, 48, 829-836 (2008).

DOI: 10.1002/pen.21019

[10] Aou K., Hsu S. L., Kleiner L. W., Tang F-W.: Roles of conformational and configurational defects on the physical aging of amorphous poly(lactic acid). Journal of Physical Chemistry B, 111, 12322-12327 (2007). DOI: 10.1021/jp074509t

[11] Pan P. J., Zhu B., Inoue Y.: Enthalpy relaxation and embrittlement of poly(L-lactide) during physical aging. Macromolecules, 40, 9664-9671 (2007).

DOI: $10.1021 / \mathrm{ma} 071737 \mathrm{c}$

[12] Liu C-H., Nairn J. A.: Using the essential work of fracture method for studying physical aging in thin, ductile, polymeric films. Polymer Engineering and Science, 38, 186-193 (1998).

DOI: $10.1002 /$ pen.10179

[13] Karger-Kocsis J., Bárány T., Moskala E. J.: Plane stress fracture toughness of physically aged plasticized PETG as assessed by the essential work of fracture (EWF) method. Polymer, 44, 5691-5699 (2003). DOI: 10.1016/S0032-3861(03)00590-1

[14] Ho C. H., Vu-Khanh T.: Physical aging and time-temperature behavior concerning fracture performance of polycarbonate. Theoretical and Applied Fracture Mechanics, 41, 103-114 (2004).

DOI: $10.1016 /$ j.tafmec.2003.11.008

[15] Bárány T., Ronkay F., Karger-Kocsis J., Czigány T.: In-plane and out-of-plane fracture toughness of physically aged polyesters as assessed by the essential work of fracture (EWF) method. International Journal of Fracture, 135, 251-265 (2005).

DOI: $10.1007 / \mathrm{s} 10704-005-3947-2$
[16] Bárány T., Földes E., Czigány T.: Effect of thermal and hygrothermal aging on the plane stress fracture toughness of poly(ethylene terephthalate) sheets. Express Polymer Letters, 1, 180-187 (2007).

DOI: $10.3144 /$ expresspolymlett.2007.28

[17] NatureWorks ${ }^{\circledR}$ PLA Polymer 2002D - Data Sheet (2005)

[18] NatureWorks ${ }^{\circledR}$ PLA Polymer 4032D - Data Sheet (2006).

[19] Li H., Huneault M. A.: Effect of nucleation and plasticization on the crystallization of poly(lactic acid). Polymer, 48, 6855-6866 (2007).

DOI: 10.1016/j.polymer.2007.09.020

[20] Xiao H. W., Lu W., Yeh J-T.: Effect of plasticizer on the crystallization behavior of poly(lactic acid). Journal of Applied Polymer Science, 113, 112-121 (2009). DOI: 10.1002/app.29955

[21] Carrasco F., Pagès P., Gámez-Pérez J., Santana O. O., Maspoch M. L.: Processing of poly(lactic acid): Characterization of chemical structure, thermal stability and mechanical properties. Polymer Degradation and Stability, 95, 116-125 (2010).

DOI: $10.1016 /$ j.polymdegradstab.2009.11.045

[22] Clutton E.: Essential work of fracture. in 'Fracture mechanics testing methods for polymers, adhesives and composites' (eds.: Moore D. R., Williams J. G., Pavan A.) Vol 28, 177-195 (2001).

DOI: $10.1016 /$ S1566-1369(01)80033-9

[23] Ganß M., Satapathy B. K., Thunga M., Weidisch R., Pötschke P., Jehnichen D.: Structural interpretations of deformation and fracture behavior of polypropylene/ multi-walled carbon nanotube composites. Acta Materialia, 56, 2247-2261 (2008).

DOI: 10.1016/j.actamat.2008.01.010

[24] Gámez-Pérez J., Muñoz P., Velasco J. I., Martínez A. B., Maspoch M. L.: Determination of essential work of fracture in EPBC sheets obtained by different transformation processes. Journal of Material Science, 40, 1967-1974 (2005).

DOI: $10.1007 / \mathrm{s} 10853-005-1218-2$

[25] Wong J. S. S., Ferrer-Balas D., Li R. K. Y., Mai Y-W., Maspoch M. L., Sue H-J.: On tearing of ductile polymer films using the essential work of fracture (EWF) method. Acta Materialia, 51, 4929-4938 (2003).

DOI: 10.1016/S1359-6454(03)00335-5

[26] Martínez A. B., Gámez-Pérez J., Sanchez-Soto M., Velasco J. I., Santana O. O., Maspoch M. L.: The essential work of fracture (EWF) method - Analyzing the post-yielding fracture mechanics of polymers. Engineering Failure Analysis, 16, 2604-2617 (2009).

DOI: 10.1016/j.engfailanal.2009.04.027

[27] Bárány T., Czigány T., Karger-Kocsis J.: Application of the essential work of fracture (EWF) concept for polymers, related blends and composites: A review. Progress in Polymer Science, 35, 1257-1287 (2010). DOI: 10.1016/j.progpolymsci.2010.07.001 
[28] Gámez-Pérez J., Santana O., Martinez A. B., Maspoch M. L.: Use of extensometers on essential work of fracture (EWF) tests. Polymer Testing, 27, 491-497 (2008). DOI: $10.1016 /$ j.polymertesting.2008.02.002

[29] Mo X. Q., Sun X. Z.: Effects of storage time on properties of soybean protein-based plastics. Journal of Polymers and the Environment, 11, 15-22 (2003). DOI: 10.1023/A:1023831411521

[30] Aref-Azar A., Hay J. N.: Physical ageing in glassy polymers. An i.r. spectroscopic investigation of poly (ethylene terephthalate). Polymer, 23, 1129-1132 (1982). DOI: 10.1016/0032-3861(82)90366-4

[31] Cowie J. M. G., Harris S., McEwen I. J.: Physical aging in poly(vinyl acetate). 2. Relative rates of volume and enthalpy relaxation. Macromolecules, 31, 2611-2615 (1998). DOI: $10.1021 / \mathrm{ma} 970287 \mathrm{t}$

[32] Kolstad J. J.: Crystallization kinetics of poly(L-lactide-co-meso-lactide). Journal of Applied Polymer Science, 62, 1079-1091 (1996).

DOI: 10.1002/(SICI)1097-4628(19961114)62:7<1079 $\because$ AID-APP14>3.0.CO;2-1

[33] Hernández Sánchez F., Molina Mateo J., Romero Colomer F. J., Salmerón Sánchez M., Gómez Ribelles J. L., Mano J. F.: Influence of low-temperature nucleation on the crystallization process of poly(L-lactide). Biomacromolecules, 6, 3283-3290 (2005). DOI: $10.1021 / \mathrm{bm} 050323 \mathrm{t}$

[34] Salmerón Sánchez M., Gómez Ribelles J. L., Hernández Sánchez F., Mano J. F.: On the kinetics of melting and crystallization of poly(L-lactic acid) by TMDSC. Thermochimica Acta, 430, 201-210 (2005). DOI: $10.1016 /$ j.tca.2005.01.066
[35] Fischer E. W., Sterzel H. J., Wegner G.: Investigation of structure of solution grown crystals of lactide copolymers by means of chemical-reactions. Colloid and Polymer Science, 251, 980-990 (1973).

DOI: $10.1007 / \mathrm{BF} 01498927$

[36] Joziasse C. A. P., Veenstra H., Grijpma D. W., Pennings A. J.: On the chain stiffness of poly(lactide)s. Macromolecular Chemistry and Physics, 197, 22192229 (1996).

DOI: 10.1002/macp.1996.021970713

[37] Perego G., Cella G. D., Bastioli C.: Effect of molecular weight and crystallinity on poly(lactic acid) mechanical properties. Journal of Applied Polymer Science, 59, 37-43 (1996).

DOI: $10.1002 /($ SICI)1097-4628(19960103)59:1<37:: AID-APP6>3.0.CO;2-N

[38] Nascimento L., Gámez-Pérez J., Santana O. O., Velasco J. I., Maspoch M. L.: Effect of the recycling and annealing on the mechanical and fracture properties of poly(lactic acid). Journal of Polymers and the Environment, 18, 654-660 (2010). DOI: $10.1007 / \mathrm{s} 10924-010-0229-5$

[39] Park S-D., Todo M., Arakawa K.: Effect of annealing on the fracture toughness of poly(lactic acid). Journal of Materials Science, 39, 1113-1116 (2004).

DOI: 10.1023/B:JMSC.0000012957.02434.1e

[40] Kinloch A. J., Young R. J.: Fracture behaviour of polymers. Applied Science, London (1983).

[41] Mai Y-W., Cotterell B., Horlyck R., Vigna G.: The essential work of plane-stress ductile fracture of linear polyethylenes. Polymer Engineering and Science, 27, 804-809 (1987).

DOI: $10.1002 /$ pen.760271106

[42] Arkhireyeva A., Hashemi S.: Fracture behaviour of polyethylene naphthalate (PEN). Polymer, 43, 289300 (2002).

DOI: 10.1016/S0032-3861(01)00623-1 